\title{
Autonomia e Motivação em narrativas de aprendizes de português como língua estrangeira ${ }^{1}$
}

Fernanda Sousa Carvalho

Universidade Federal de Minas Gerais - UFMG

Fundação de Amparo à Pesquisa do Estado de Minas Gerais - FAPEMIG

Neste artigo, discuto os resultados de minha pesquisa dentro do projeto AMFALE - Autonomia em um Modelo Fractal de Aquisição de Língua Estrangeira. Com base em conceitos de autonomia e motivação e na correlação entre eles, analiso narrativas de aprendizes de português como língua estrangeira em Belo Horizonte. Tais análises atestam que a experiência de aprendizagem inserida em uma comunidade de falantes da língua-alvo propicia autonomia, à medida que caracteriza motivação intrínseca e/ou integrativa e oferece uma variedade de possibilidades para o aprendiz agir autonomamente com relação à própria aprendizagem.

In this article, I discuss the results of my research within the project AMFALEAutonomia em um Modelo Fractal de Aquisição de Língua Estrangeira. Based on concepts of autonomy and motivation and in the correlation between them, I analyze narratives of learners of Portuguese as a foreign language in Belo Horizonte. Such analysis testify that the learning experience in a community of speakers of the target language makes autonomy possible, as it characterizes intrinsic and/or integrative motivation, providing a variety of possibilities for the learner to act with autonomy towards his own learning.

\section{Introdução}

Muito tem sido discutido sobre autonomia na aprendizagem de línguas estrangeiras (LE) como característica importante que permite ao aprendiz desenvolver sua aquisição com base em seus próprios interesses e habilidades. Nesse sentido, conceitos de autonomia têm sido propostos ao longo dos tempos, de forma a permitir a identificação de fatores que

\footnotetext{
${ }^{1}$ Trabalho orientado pela Dra. Vera Lúcia Menezes de Oliveira e Paiva, com apoio da FAPEMIG.
} 
caracterizam o aprendiz autônomo e um conseqüente aprofundamento nos estudos sobre abordagens pedagógicas que promovam a autonomia do aprendiz.

Voltado para essa questão, o projeto AMFALE (Autonomia em um Modelo Fractal de Aquisição de Língua Estrangeira), coordenado pela professora Vera Lúcia Menezes de Oliveira e Paiva, da Faculdade de Letras da UFMG, tem buscado relacionar fatores que caracterizam autonomia ao sistema complexo de aprendizagem de uma língua estrangeira. Como parte desse projeto, minha pesquisa teve por objetivos: revisar a literatura, no intuito de levantar conceitos de autonomia, detectar os fatores que caracterizam um aprendiz autônomo e identificar tais fatores em aprendizes de português como língua estrangeira, através da análise de narrativas. Tendo atestado, na revisão da literatura, a importância da relação entre autonomia e motivação na aprendizagem de LE, incluí em meu trabalho a observação dessa relação nas narrativas analisadas.

A idéia de analisar narrativas de aprendizes para detectar indícios de autonomia na experiência de aprendizagem está fortemente relacionada ao próprio conceito desse termo. Como são resultados da reflexão do aprendiz sobre seu próprio processo de aprendizagem, entendo que narrativas sejam materiais ricos em informações que permitem comprovar ou contradizer o que se tem discutido sobre autonomia . Como se explicitará mais adiante, uma das características do aprendiz autônomo é a consciência do próprio processo de aprendizagem.

No presente artigo, aponto os conceitos de autonomia mais recorrentes na literatura, assim como os de motivação, e averiguo a aplicabilidade desses à análise das narrativas coletadas entre estrangeiros aprendizes de português no Brasil.

\section{Fundamentação teórica}

Como já foi dito anteriormente, o conceito de autonomia é muito complexo e varia relativamente na literatura. Tentei selecionar, durante a pesquisa, as idéias mais recorrentes e que se relacionam mais diretamente ao contexto de aprendizagem pesquisado.

Primeiramente, deve-se reconhecer que autonomia é uma idéia presente em diversas áreas. Benson e Voller (1997, p. 4) associam o conceito de autonomia, assim como o de independência, ao pensamento liberal ocidental do século XXI, considerando-as palavras-chave nas áreas da 
filosofia, psicologia, política e educação. Segundo os autores, em filosofia e psicologia, os termos autonomia e independência estão relacionados à "capacidade de o indivíduo agir como membro responsável da sociedade". 2 $\mathrm{Na}$ área da educação, estes termos dizem respeito à "formação do indivíduo como centro de uma sociedade democrática". ${ }^{3}$ Já na área política, autonomia e independência significam "liberdade em relação a um controle externo". ${ }^{4}$

Um trabalho interessante que também considera autonomia como basicamente uma idéia ocidental é o de Ho e Crookallt (1995). Usando como argumento a cultura chinesa e o respeito que estudantes chineses mantêm em relação à autoridade do professor, os autores afirmam que estudantes orientais tendem a se sentir desconfortáveis quanto a agir com autonomia. Essa questão é importante para a minha pesquisa, uma vez que alguns dos informantes são orientais.

Quanto ao conceito de autonomia em ensino de línguas, Benson (1997, p.18-25) aponta três "versões", a saber:

1) versão técnica: autonomia como aprendizagem de uma língua fora do contexto de uma instituição educacional e sem a intervenção de um professor;

2) versão psicológica: autonomia como capacidade do aprendiz de assumir responsabilidade por seu próprio processo de aprendizagem;

3) versão política: autonomia como controle sobre o processo e o conteúdo - os contextos externo e interno - da aprendizagem.

Considerando as variações conceituais presentes na literatura, Benson e Voller (1997, p.1-2) apontam cinco maneiras diferentes de se tratar autonomia:

1) "como situações em que aprendizes estudam completamente sozinhos;

2) como uma série de habilidades que podem ser aprendidas e aplicadas em uma aprendizagem autodirecionada;

3) como uma capacidade inata que é reprimida pelo ensino institucionalizado;

\footnotetext{
${ }^{2}$ Todas as citações nesse artigo foram por mim traduzidas. "(...) the capacity of the individual to act as a responsible 'member of society' (...)."

3 "(...) the formation of the individual as the core of a democratic society."

4 "freedom from external control".
} 
4) como o exercício da responsabilidade do aprendiz pela sua própria aprendizagem;

5) como o direito dos aprendizes de determinar a direção de sua própria aprendizagem".

A revisão bibliográfica permitiu-me observar que uma noção correntemente citada nos trabalhos sobre autonomia é aquela originalmente usada por Holec (1980, p. 3): "autonomia é a habilidade de se responsabilizar por sua própria aprendizagem". ${ }^{5}$ Outro trabalho importante para a definição do termo é o de Dickinson (1994). O autor apresenta a autonomia como sendo o grau máximo de autodirecionamento na aprendizagem, diferindo de Holec (1980), para quem a autonomia é a habilidade da qual o autodirecionamento é a prática. Holec $(1981$, p. 3) afirma ainda que, embora a aprendizagem auto-direcionada implique aprendiz autônomo, o último não necessariamente envolve o primeiro: um aprendiz pode ter a capacidade de controlar seu aprendizado sem necessariamente utilizar essa capacidade ao máximo quando ele decide aprender.

Nota-se logo que, para se entender o conceito de autonomia, devese primeiro compreender outros termos a este relacionado, muitas vezes até confundidos com ele: auto-instrução, autodirecionamento, semiautonomia instrução individualizada. Nesse sentido, vale considerar as definições de Dickinson (1987, p.11). Segundo ele, a auto-instruçãoé caracterizada por situações em que aprendizes trabalham sem o controle direto do professor. Autodirecionamento implica atitude para com a tarefa de aprendizagem, na qual o aprendiz assume responsabilidade por todas as decisões relacionadas à sua aprendizagem, sem necessariamente implementar essas decisões. Já a autonomia é definida por ele como a situação em que o aprendiz é totalmente responsável por todas as decisões relacionadas à sua aprendizagem e à implementação dessas decisões. Nesse estágio não há o envolvimento de um professor ou de uma instituição e o aprendiz também é independente de materiais especialmente preparados. Dickinson propõem ainda o termo semi-autonomia: o estágio em que aprendizes estão se preparando para a autonomia. E para definir instrução individualizada, cita Chaix e O'Neil (1978): o processo de aprendizagem preparado e adaptado para um certo indivíduo, considerando-se suas características individuais.

5 "the ability to take charge of one's own learning". 
Pode-se concluir que Dickinson considera haver um estado ideal, em que a responsabilidade do aprendiz dentro de seu processo de aprendizagem é total; esse é o nível máximo, o que o autor define como autonomia, sendo os níveis abaixo desse considerados semi-autonomia. No entanto, os exemplos encontrados na literatura e aqueles analisados aqui levam a acreditar que esse nível máximo de autonomia seja praticamente impossível de se alcançar. Isso porque parece difícil encontrar alguma atitude ou tarefa de aprendizagem que não seja minimamente influenciada por alguém, seja pelo uso de um material didático diferente daquele usado em sala de aula ou pela simples correção que um falante nativo pode fazer durante uma conversa informal com o aprendiz.

A idéia de que existem graus de autonomia também pode ser observada em outros autores, o que ajuda a identificar as características de um aprendiz autônomo. Littlewood (1996, p. 429) sugere uma progressão para caracterizar o nível de autonomia na aprendizagem de línguas. Primeiro, o aprendiz desenvolve uma capacidade de fazer as próprias escolhas em gramática e vocabulário. Depois, passa a escolher os significados a serem expressos e as estratégias de comunicação a serem usadas para alcançar metas; desenvolve a capacidade de tomar decisões mais abrangentes sobre metas, significados e estratégias; começa a escolher e a moldar seus próprios contextos de aprendizagem. A partir daí, o aprendiz torna-se capaz de tomar decisões em questões tradicionalmente de responsabilidade do professor; participa na determinação da natureza e do avanço de seu próprio programa de estudos; e, por fim, torna-se capaz de usar a língua independentemente em situações de sua escolha fora da sala de aula.

Enquanto processo desenvolvido em diferentes graus por aprendizes, a autonomia depende de certas condições para existir. Holec (1981, p. 9) estabelece duas condições: que o aprendiz tenha capacidade de se responsabilizar por sua aprendizagem (saber fazer escolhas) e que a organização de seu processo de aprendizagem permita-lhe exercer essa capacidade.

Essas condições representam a idéia de que a autonomia não é apenas uma capacidade de fazer suas próprias escolhas, mas depende também da vontade do aprendiz e da possibilidade de usar essa capacidade. É interessante observar como o contexto de aprendizagem analisado aqui favorece a segunda condição: estar num país onde a língua alvo é falada oferece um amplo leque de oportunidades de controle da própria aprendizagem, pelas 
possibilidades variadas de meios, inclusive não-institucionalizados. Mas é claro que essa vantagem de nada adianta se o aprendiz não tiver a habilidade de agir com autonomia - não souber e/ou não quiser tomar suas próprias decisões.

Outro autor que discute as condições para o desenvolvimento de autonomia é Little. ${ }^{6}$ Segundo ele, há um consenso entre os estudiosos de que a prática de autonomia do aprendiz requer introspecção, atitude positiva, capacidade de reflexão e prontidão para ser ativo no autogerenciamento e na interação com os outros.

Para relacionar as características atribuídas ao aprendiz autônomo, vale citar aqui o trabalho de Littlewood (1996, p. 431), que descreve três extensões em que um indivíduo pode agir com autonomia: como comunicador (usar a língua com criatividade e usar estratégias apropriadas para comunicar significados em situações específicas); como aprendiz (dedicar-se a um trabalho independente e usar estratégias de aprendizagem apropriadas, tanto dentro quanto fora da sala de aula); e como pessoa (dentro do processo de aprendizagem de LE, expressar significados pessoais e criar contextos pessoais de aprendizagem).

Para Littlewood (1996, p. 428), uma pessoa autônoma tem a capacidade de realizar as escolhas que governam suas ações. Mas essa capacidade, segundo o autor, depende da habilidade (ability) para fazer escolhas independentes e da vontade para realizá-las. Essa habilidade para fazer escolhas, por sua vez, está relacionada ao conhecimento das alternativas e das habilidades ( skills) necessárias para cumprir aquelas que são apropriadas. A prontidão e a boa vontade para cumprir as escolhas dependem da motivação e da confiança para assumir responsabilidade pelas escolhas necessárias.

Além de autonomia, outro conceito que parece imprescindível para essa pesquisa é o de motivação, que se relaciona à atitude do indivíduo para com sua própria aprendizagem, sendo ao mesmo tempo influenciadora da e influenciada pela autonomia do aprendiz. Segundo Paiva (2004, p. 5), "a motivação é determinada pelos graus de autonomia, além de outros fatores, tais como, necessidades, crenças sobre aprendizagem, experiências passadas de aprendizagem ou histórias de aprendizagem, afetividade, autoestima, etc".

\footnotetext{
${ }^{6}$ LITTLE, David. Disponível em: http://www.lang.ltsn.ac.uk/resources/goodpractice.
} aspx?resourceid $=1409 \#$ toc_8583. 
O trabalho de Dickinson (1995) apresenta grandes contribuições para a compreensão da relação autonomia/motivação. Segundo ele, definições de motivação dizem respeito ao que o aprendiz está preparado para aprender e a quanto esforço ele está preparado para empenhar para aprender isso (p. 168). O autor cita ainda a definição de Keller (in CROOKES; SCHMIDT, 1991, p. 389 apud DICKINSON, 1995, p.168): "motivação se refere às escolhas que as pessoas fazem, como quais experiências ou quais metas elas irão acessar ou evitar e o grau de esforço que elas empenharão nesse sentido". 7

O autor também apresenta teorias sobre motivação. Entre elas, os conceitos de motivação intrínseca extrinseca (DECI; RYAN, 1985 apud DICKINSON, 1995, p. 168), relacionadas à motivação cognitiva, e à teoria da atribuição:

1) motivação intrínseca: quando o aprendiz está interessado em alcançar melhores resultados na aprendizagem por motivos próprios;

2) motivação extrínseca: quando, ao contrário, o interesse em ser bemsucedido na aprendizagem está em recompensas ou pressões externas.

O autor argumenta que a motivação intrínseca, enquanto independente de pressões externas, é um indício da forte ligação entre autonomia e motivação.

3) teoria da atribuição: relaciona motivação às causas que o aprendiz acredita serem responsáveis por seu sucesso ou falha. Sugere que, quando o aprendiz acredita em causas fixas (como a habilidade) ou causas externas para as suas falhas (como dificuldade de tarefas), ele não persiste em tentar melhorar; mas o aprendiz que acha que seu sucesso ou suas falhas resultam de seus próprios esforços tende a assumir responsabilidade por seu aprendizado. Essa teoria se relaciona à autonomia na aprendizagem, no que evidencia que aprendizes que acreditam ter controle sobre seu aprendizado tendem a ser mais bemsucedidos que outros (DICKINSON, 1995, p. 172).

Dickinson (1995, p.167) também cita o modelo sócio-psicológico, que relaciona motivação a atitudes para com a comunidade de falantes da língua-alvo, e sustenta que aprendizes com interesse em interagir com tais falantes - motivação integrativa - são mais bem-sucedidos na aprendizagem

\footnotetext{
7 "Motivation refers to the choices people make as to what experiences or goals they will approach or avoid, and the degree of effort they will exert in that respect."
} 
da língua alvo do que aqueles que o fazem por razões instrumentais. A relação autonomia/motivação fica clara quando o autor afirma que ambas compartilham alguns conceitos-chave atribuídos ao aprendiz: independência, responsabilidade e escolha (p.168).

Por fim, para a busca de indícios de autonomia dentro do contexto que pretendia analisar, uma definição de autonomia pareceu-me essencial:

"[Autonomia é] um sistema sócio-cognitivo complexo, que se manifesta em diferentes graus de independência e controle sobre o próprio processo de aprendizagem, envolvendo capacidades, habilidades, atitudes, desejos, tomadas de decisão, escolhas, e avaliação tanto como aprendiz de língua ou como seu usuário, dentro ou fora da sala de aula" (PAIVA, 2006, p. 88-89). ${ }^{8}$

Essa definição será útil na análise de narrativas de estrangeiros aprendendo português no Brasil, à medida que realça o aspecto social do sistema. Os fatores mais importantes a serem considerados nesse contexto envolvem atitudes dos aprendizes para com a comunidade de falantes nativos e a interação entre eles. Como mostrarei mais adiante, essa interação social é apontada por quase todos os informantes como estratégia eficaz e causa para o sucesso de sua aprendizagem.

\section{Metodologia}

Para identificar fatores que caracterizam autonomia, foram coletadas narrativas de aprendizagem entre estrangeiros aprendizes de português no Brasil. É importante ressaltar que foram analisadas somente as ações dos aprendizes, sem levantamento dos métodos aos quais eles são expostos em sala de aula. Todas as informações analisadas foram relatadas pelos próprios aprendizes, já que não é objetivo do projeto avaliar o papel dos professores ou do sistema de ensino em que o aprendiz está inserido, mas, sim e somente, as ações do próprio aprendiz.

O material analisado foi coletado em forma de narrativas orais e escritas. Das 43 narrativas coletadas, 30 são de alunos do curso de Português para Estrangeiros do CENEX/FALE, uma é de uma aluna estrangeira que

\footnotetext{
8 "Autonomy is a complex socio-cognitive system, manifested in different degrees of independence and control of one's own learning process, involving capacities, abilities, attitudes, willingness, decision making, choices, planning, actions, and assessment either as a language learner or as a communicator inside or outside the classroom."
} 
cursa graduação em português na FALE, uma é de um estrangeiro aprendiz de português sem vínculo com o contexto formal de aprendizagem da língua, e 14 são de intercambistas porto-riquenhos em passagem curta pelo Brasil (entrevistados pela estagiária Vanessa Lacerda, do Núcleo de Ensino e Pesquisa de Português para falantes de outras línguas, coordenado pela Profa. Dra. Regina L. Péret Dell'Isola, da FALE/UFMG). Ao coletar as narrativas, foi solicitado ao aprendiz que falasse sobre seu processo de aprendizagem de português, desde o início até o presente momento, enfatizando suas estratégias de aprendizagem, as evoluções observadas por eles no próprio processo e uma avaliação das dificuldades que enfrentaram ou têm enfrentado na aprendizagem de português nos contextos em que a experimentaram. Das 43 narrativas coletadas, apenas duas estão totalmente em inglês e outras quatro misturam português e inglês; todo o restante está em português. Durante a transcrição, procurei evitar alterações, limitandome a fazer correções gramaticais, mas sem alterar a informação transmitida pelo aprendiz.

Optei por não levar em consideração certos fatores como o sexo e a idade dos entrevistados (apesar de esses dados terem sido coletados) porque discuti-los ultrapassaria os objetivos propostos pelo projeto. Deve-se reconhecer, entretanto, a importância de tais fatores para estudos sobre autonomia como possíveis influenciadores.

As narrativas em áudio com as respectivas transcrições foram transferidas para a homepage do projeto, onde se encontram disponíveis para consulta no endereço: http://www.veramenezes.com/nar-aud.htm.

Dessa maneira, tendo coletado os dados e revisado a literatura sobre o tema, procedi à análise das narrativas em busca de características que indicassem um aprendizado autônomo ou contradissessem algum postulado já estabelecido por estudiosos do tema.

\section{Narrativas}

As narrativas coletadas entre estrangeiros aprendizes de português no Brasil, como já se esperava, ofereceram muitos exemplos que confirmam o que se tem discutido na literatura em termos de autonomia na aprendizagem de uma língua estrangeira.

Tendo em mente as definições de aprendiz e, especialmente, a progressão de níveis de autonomia de Littlewood (1996, p. 429), observei a ocorrência dos seguintes fatores, reconhecidos como indicadores de autonomia: 
- consciência do próprio processo de aprendizagem de português necessidades, interesses, falhas, sucessos, progressos;

- escolhas em gramática e vocabulário de acordo com os interesses pessoais de comunicação;

- tomada de decisão sobre metas, significados e estratégias;

- escolha e adaptação do próprio contexto de aprendizagem;

- tomada de decisões em assuntos tradicionalmente de responsabilidade do professor, como por exemplo, a escolha de materiais e de tópicos a serem enfatizados;

- uso do português em situações de própria escolha fora da sala de aula.

- busca de meios e materiais diferentes daqueles disponibilizados pela instituição de ensino formal;

- motivação, na maioria dos casos intrínseca e/ou integrativa;

- exercício de autonomia como comunicador e/ou como aprendiz e/ou como pessoa, beneficiado pela situação de aprendizagem - estudando português durante a estadia no Brasil.

Esses fatores serão apontados nas análises das narrativas que seguem. Considere-se o seguinte trecho como primeiro exemplo:

\section{Narrativa 1:}

(...) Eu preciso aprender português agora para treinar os missionários brasileiros para serviço fora do Brasil e dentro... aqui [no] Brasil também. E, por causa d[isso], eu preciso aprender bem, falar bem. E esse curso ... Português para Estrangeiros, intermediário, é minha primeira aula no português. Mas tenho umas estratégias para aprender. Por exemplo, comprei um CD, ou DVD, para aprender no computador... se chama [...] Essa companhia que está publicando os materiais para aprender vários... várias línguas. Comprei um de português brasileiro e eu estou estudando mesmo agora, usando esse CD e programa no computador. Depois, tenho também um tutor particular e tenho lições três vezes por semana, de manhã, por duas horas cada aula. E depois, tenho esse curso também, mas em casa eu estou estudando português mais ou menos de três a cinco horas por dia. Eu estou lendo os materiais das aulas aqui da UFMG, no jornal, nas revistas, na TV também. Tenho também os materiais mais orientados na gramática mesmo, do português, porque os materiais que estamos usando no curso [português] intermediário p[ara] estrangeiros, tem... esses materiais têm gramática dentro dos exercícios, mas eu preciso [de uma] apresentação mais clara, mais organizada da gramática. Então eu 
estou usando todos esses tipos de materiais e, ao final desses quatro meses, agora, eu posso falar não muito bem mas eu posso [me] expressar.?

Esse é um dos casos detectados de motivação extrínseca, uma vez que o aprendiz norte-americano está estudando para cumprir melhor suas tarefas profissionais. No entanto, as informações não são suficientes para comprovar a afirmação de Dickinson (1995) de que aprendizes intrinsecamente motivados são mais bem-sucedidos do que aprendizes extrinsecamente motivados. O que está claro é que esse aprendiz é muito esforçado e sua busca de intensificar e agilizar seu processo de aprendizagem excluem uma possibilidade de insucesso. Para tanto, ele fez uma série de escolhas: decidindo seguir um curso de português para estrangeiros, complementando com aulas particulares, selecionando o material a ser usado fora da sala de aula, determinando o tempo a ser dedicado às atividades. Essas escolhas lhe conferem um certo grau de autodirecionamento e também de autonomia, que ao mesmo tempo é limitado pelo fato de o aprendiz ter dois professores orientando diretamente seus estudos e de usar materiais especialmente elaborados. Outro indício de autonomia nesse exemplo está na busca de materiais autênticos (jornais, revistas, TV) e na escolha de conteúdo a ser enfatizado (gramática, no caso) com base nas próprias necessidades.

Vejamos um segundo exemplo:

\section{Narrativa 2:}

Pra falar a verdade, eu não estudo muito português, de maneira a pegar um livro e estudar. Eu devo fazer isso, mas eu não... Realmente, eu tenho muitos compromissos, eu trabalho e tudo mais, então eu não tenho... Eu até tenho tempo, mas eu não faço. Aí então eu acho que o que eu aprendi até agora de português é na aula mesmo, falando com as pessoas no diaa-dia, e através da televisão, da convivência com a língua. E é agora que eu tenho um pouco mais de facilidade com a língua. Eu estou lendo muito. Que eu acho, realmente, que eu poderia estudar gramática, poderia estudar conjugação de verbo, concordância, pronome, preposições e tudo mais, mas o que realmente vai, vamos dizer, gravar a língua na sua cabeça é através de ler a língua, eu acho, pra mim pessoalmente. A minha área é mais pra belas artes, então eu gosto muito da música brasileira. Então, eu estou lendo, por exemplo, agora, um livro sobre a Tropicália, na época de fim dos anos sessenta e início dos anos setenta. E eu li vários. Esse mês

\footnotetext{
${ }^{9}$ http://www.veramenezes.com/audiop33.htm.
} 
passado, precisamos ler um livro de Betinho, que eu acho muito interessante, porque fala de $\mathrm{BH}$, fala de Minas Gerais, e tudo mais. Eu assisto quase..., tem um canal que passa filmes brasileiros, documentários, curta metragens, e quase todos eu assisto muito na televisão. Como por exemplo, um filme sobre as favelas. São Paulo, por exemplo, tem pessoas que falam português de um jeito totalmente diferente do que aqui, por exemplo, o que é interessante. Assistindo o jornal nacional, essas coisas. Mas, eu acho muito mais... Tem tempo que eu estou aqui, de convivência com a língua, porque você acaba errando muitas coisas e, assim, depois você pode ficar falando a mesma coisa durante seis meses, e um dia alguém vai falar com você: "Olha, não é assim que fala". Você vai ouvir alguém falando uma coisa que você sabe que é errado, o tempo inteiro, sem perceber e depois a ficha cai: "não é assim que fala". Então, eu acho muito mais convivência com língua... Mas pra aprender... Eu sou professor de inglês, então eu posso ver o outro lado, das pessoas que estão aprendendo uma língua sem contato com ela. É uma coisa bem diferente, é preciso muito mais dedicação. Realmente, por isso que eu falo que eu não pego os livros de gramática e tudo mais, porque eu não precisei até agora, porque a convivência dia a dia com a língua ajuda nisso. (...) Você pode chegar até um certo ponto de fluência e tudo mais, você podia entender a gramática e todas essas coisas, mas pra realmente desenvolver o lado da fluência oral e de ouvir a língua, entender como que é usada, e tudo mais, eu acho que você precisa morar no lugar que fala essa língua. ${ }^{10}$

Na narrativa 2, o aprendiz norte-americano afirma que freqüenta o curso de português para estrangeiros, mas enfatiza o contato direto com a língua como o fator principal para o sucesso de sua aprendizagem. Para ele, a falta de tempo para se dedicar ao estudo da gramática é compensado pela exposição direta a materiais autênticos e à interação com falantes nativos. O aprendiz se baseia na sua própria experiência como professor de inglês para alunos brasileiros para considerar que o fato de estar em contato com a língua alvo é um privilégio. É possível perceber indícios de autodirecionamento e de autonomia nessa narrativa, à medida que o aprendiz, a partir da crença de que o contato com o português é mais útil para a sua aprendizagem, dirige seu próprio processo, buscando meios que preencham as suas necessidades particulares e que se adaptem às suas facilidades e dificuldades. Essa autonomia, porém, não é total, já que o aprendiz está ligado a uma instituição de ensino. Pode-se dizer, ainda, que sua motivação é intrínseca, pelo fato

\footnotetext{
${ }^{10}$ http://www.veramenezes.com/audiop11.htm.
} 
de ele estudar português por interesse próprio, e integrativa, pelo fato de ele buscar interação com a comunidade de falantes nativos.

Uma observação importante feita na análise das narrativas tem a ver com a busca dos aprendizes de um contato maior com falantes nativos, numa intenção também de interação social. Seja por falta de tempo de estudar de outras maneiras ou por realmente achar que essa é a maneira mais prática e rápida de se aprender uma língua, a conversação com nativos é sempre citada pelos informantes, relacionada às habilidades da fala e compreensão. Essa observação parece óbvia, visto que a necessidade de interação social para viver num país diferente por si só já requer tal busca, caracterizando uma motivação integrativa. Ainda quanto ao contato direto com o português, um trecho da entrevista de um intercambista porto-riquenho é bem ilustrativa: "[o]s primeiros dias foram interessantes, eu achava que estava num laboratório grande! Para mim, foi como um sonho porque eu lia... tudo, os programas... tudo em português (...)" ${ }^{11} \mathrm{O}$ aprendiz, que tem acesso a um laboratório de língua e cultura brasileiras em sua faculdade em Porto Rico, relata sua experiência no Brasil em termos da intensa exposição à língua que vivenciou. A narrativa seguinte é um exemplo da preferência dos aprendizes estrangeiros pelo contato com nativos como estratégia de aprendizagem:

\section{Narrativa 3:}

(...) Eu estou aqui no Brasil há três meses, mas eu já tinha feito duas matérias de português antes de chegar aqui no Brasil. Mas eu acho que eu não aprendi muito. Eu acho que eu aprendi a escrever e a ler muito mais que falar, na época. Eu acho que foi muito difícil aprender a falar português. Na minha cidade, em Austin no Texas, eu tinha aula três vezes por semana. Assim, eu aprendi a ler e a escrever na minha cidade. Mas para falar eu não aprendi quase nada. Eu não falei quase nada. As matérias e os professores estavam mais direcionados para o ensino da gramática, mais para ler do que falar na aula, não havia muitas perguntas para responder, não era muito comunicativo. Mas quando cheguei aqui no Brasil, eu fiz uma matéria de português para estrangeiros em seis semanas e isso me ajudou muito. Eu acho que a parte mais difícil já passou porque no começo aqui no Brasil foi muito difícil para falar. A melhor coisa que tem para estudar português

\footnotetext{
${ }^{11}$ Narrativa coletada por Vanessa Lacerda, do Núcleo de Ensino e Pesquisa de Português para falantes de outras línguas, coordenado pela Profa. Dra. Regina L. Péret Dell'Isola, da FALE/UFMG.
} 


\begin{abstract}
é ficar em um boteco e falar com as pessoas porque eu acho que eu não aprendo muito rápido com o livro, com a televisão. A televisão é boa, é um bom exercício, mas não é uma conversa. Eu só ouço a língua, mas não falo. Eu acho que a fala é importante para me expressar. Porque quando eu falo uma palavra eu vou lembrar dessa palavra depois, mas se eu não falar, eu não vou lembrar. Eu posso escutar essa palavra muitas vezes, mas se eu não falar essa palavra, eu não vou lembrar. Isso acontece muito comigo. Agora eu faço mais isso. Eu também escuto a televisão, mas quando eu cheguei aqui eu escrevi muito ainda por seis semanas, fiz resumos, também assisti filmes com a legenda, e também li jornal. Eu acho que o jornal é mais perto da língua falada do que um romance e tem muita gramática. O jornal é mais informal e o que eu mais quero aprender é a língua falada e não a escrita porque eu falo mais do que escrevo. Mas agora eu acho que eu tenho que escrever mais. Eu quero aprender a escrever porque eu acho importante e me ajuda a falar também e porque também tem gramática. ${ }^{12}$
\end{abstract}

Aqui, o aprendiz critica o sistema em que aprendia português nos EUA, considerando-o ineficiente justamente por prender o aluno a métodos tradicionais. Reconhece suas necessidades dentro do desenvolvimento de habilidades específicas, assim como busca meios próprios para supri-las, efetuando as escolhas que lhe parecem mais convenientes entre o leque de oportunidades que encontra morando no Brasil. O próprio aprendiz nota o progresso em sua aprendizagem: partindo de um início dependente do professor até um nível que eu classificaria como semi-autonomia, o qual, apesar de manter ligação com uma instituição de ensino, o aprendiz faz escolhas e toma decisões quanto a o que enfatizar em seus estudos e os meios para alcançar suas metas. Desse modo, o aprendiz norte-americano construiu uma habilidade para exercer autonomia como comunicador, como aprendiz e como pessoa. Eu diria, ainda, que a motivação nesse exemplo é, ao mesmo tempo, intrínseca e integrativa, como no exemplo anterior.

O contexto é um fator que propicia autonomia. Aprendizes vivendo no Brasil têm acesso a uma quantidade maior de recursos disponíveis para aperfeiçoar suas habilidades. Conscientes dessa disponibilidade, cabe a eles escolher quais meios utilizar.

O fato de vir ao Brasil para aprender melhor o português também pode ser citado como uma estratégia buscada pelo aprendiz, caracterizando uma escolha para a qual ele considerou seus interesses e necessidades dentro

${ }^{12}$ http://www.veramenezes.com/audiop10.htm. 
de seu próprio processo de aprendizagem, e indicando, portanto, autonomia. Alguns dos aprendizes entrevistados explicitaram essa decisão de vir ao Brasil, apresentando indícios de uma motivação intrínseca, já que o interesse de aprender melhor a língua e a cultura brasileiras partiu deles. Um exemplo é o trecho abaixo, retirado da entrevista de um intercambista porto-riquenho à Vanessa Lacerda:

\section{Narrativa 4:}

1) Há quanto tempo você estuda o português? Há um ano.

2) Onde você começou a estudá-lo?

Eu comecei lá em Porto Rico, então eu queria continuar estudando e eu decidi visitar o Brasil para praticar, melhorar.

3) E por que você escolheu o português do Brasil? (?) Eu gostei muito da cultura e...(?) e eu gostei por isso, queria conhecer.

No entanto, outros aprendizes enfatizaram uma relação diferente: começaram a aprender português porque precisavam morar no Brasil. O que se pode observar quanto à autonomia nesses casos é a escolha de como aprender português. A narrativa a seguir exemplifica tais escolhas.

\section{Narrativa 5:}

(...) I joined a social spiritual organization, and since 1989 I've been working with this organization, and through this organization I came to Brazil. So, I'm a social worker. And I teach yoga and meditation and I also give lectures on biopsychology, yoga philosophy and health. For... to teach the people in Brazil better I decided to learn Portuguese. So without Portuguese here it is difficult to teach people and people don't understand English much. So this persuaded me to learn Portuguese. So I started learning this of all one and a half month ago (...). And I feel the class is not sufficient because it is only fifty minutes, and we can only learn the basic things. But the main part is how to communicate with people, how to form sentences, specially with the so much of difficulties with the prepositions, those... feminino, masculino, for everything. So this is different from English, this is even more difficult. So I feel that I should do more exercises and training on communication to improve the Portuguese language. And we have done this and also that speaking the language outside because normally people don't speak what they write. Writing is separate words but speaking is normally joining the few words, together. So that part... we have to pay more attention to this and how to pick up the pronouns. This much... I think also... this can be improving more if we sometimes go out for theatre and learn directly in the field, like going to the beach, and what people are speaking in the beach, or going to some 
other places. So when we have friendly communication and when the students themselves are friendly to each other people learn better, 'cause I know we don't have communication between the students. We are strangers, we just come and sit, "hi", "hello", and this is it. So we don't end on like friends. So how to improve? And outside life is very busy life, muito ocupado, I've to prepare my lectures and I need somebody to translate. So to learn... just to speak Portuguese I haven't the needed time, so it's difficult for me to learn by myself . So I need to join always, being in touch with Portuguese speaking people, specially brasileiros... brasileiras e brasileiros. ${ }^{13}$

Pode-se classificar a motivação desse aprendiz como extrínseca, uma vez que uma necessidade externa o leva a estudar português. É interessante observar aqui a ênfase que o aprendiz dá à necessidade de estabelecer comunicação com falantes nativos e com seus colegas de curso para facilitar a aprendizagem de português, ao mesmo tempo em que afirma ser necessário um tempo maior de aula. Esse fato nos leva a perceber que há um certo grau de autodirecionamento nesse aprendiz, mas não uma autonomia propriamente dita, uma vez que ele parece dependente do contexto da sala de aula e não explora totalmente as oportunidades que cita para se comunicar em português.

Considere-se, agora, a seguinte narrativa:

\section{Narrativa 6:}

Eu tenho quatro anos aqui no Brasil, e eu estudei dois meses na Argentina antes de vir para aqui. Mas duas horas por semana é pouco tempo, né? Então, quando vim aqui, não sabia nada, assim, não entendia nada, o que estavam falando, nem nada. Então para mim foi começar do zero, mesmo. E na faculdade, estou... é o meu terceiro período, tem um ano e meio, já. (...) Eu adoro português. (...) Eu gosto de línguas, mas eu não conhecia, nunca tive contato com português até eu vir aqui, nem imaginei que eu iria ter. E... então eu sempre quis estudar inglês e sei lá o que, mas quando vim aqui e comecei a ter contato, contato mesmo com língua, adorei. (...) Então eu gostaria de, como professora de português, sabe, fazer as pessoas gostarem de português mesmo. Porque eu vejo que não gostam, falam que é difícil, que não sabem, seu lá o que. E eu acho lindo, eu gosto muito, muito. (...) Quando cheguei aqui eu tive aulas particulares que a empresa do... onde meu marido trabalhava mandava a professora em casa, para mim e para o meu filho. Aí foram, não lembro, três, quatro meses, todo dia, a professora todo dia. Mas eu acho que a gente aprende mesmo saindo na rua, indo no supermercado, falando errado, escutando, prestando

\footnotetext{
${ }^{13}$ http://www.veramenezes.com/audiop13.htm.
} 
atenção. Eu acho que não... só em casa, estudando assim, não adianta, não. Tem que sair e... entrar na faculdade foi ótimo. Internet é bom, bate-papo, né, é muito bom. É... tem que ter cuidado, porque no... na sala de batepapo é outra língua, né, também. Então você aprende mais... às vezes aprende coisas, gírias mesmo. Mas eu acho que foi bom, também. Como as pessoas sabiam que eu era estrangeira, então elas me ajudavam. Foi meu primeiro passo, assim, na escrita mesmo do português. E aqui na faculdade, né. Aqui tentando mesmo saber por que, a gramática, e tudo isso.

- E como era estudar português na Argentina?

Foi uma experiência meio assim, bem básica, né. Porque o meu professor era um argentino que sabia português porque ele trabalhava para a Varig, lá em Buenos Aires. Então, o português dele era assim, de contato mesmo com as pessoas, mais básico. (...) Mas não foi um professor que estudou em alguma universidade ou alguma coisa assim, não. Foi mais, foi uma experiência mesmo, de vida, de estar em contato com outras pessoas que falam português. Então, não sei se foi um grande avanço para mim, não. Não sobrou tempo, né.

- Para estudar português aqui no Brasil você tem feito algum tipo de coisa em casa, com livro, gramática?

Com livro, sim, com o livro que a professora tinha, que trazia, que ela levou para casa para gente estudar, e gramática, não. Eu... hoje foi meu primeiro contato com gramática do português mesmo, assim, gramática livro, né. Porque aqui a gente estuda, vê em algum material, mas uma gramática inteira, assim... E eu assistia muito, muita televisão, né, jornal, músicas. A Argentina escuta muita música brasileira, então, inconscientemente eu acho que... Caetano Veloso, Gal Costa, a gente escuta muito. Se bem não entende, mas, pelo menos, né, já escuta o idioma, já conhece. Então foi só isso mesmo, né. Os livros que a professora... português para estrangeiros, né. Português do Brasil para estrangeiros, muito assim, direcionado para o que a gente precisava. ${ }^{14}$

Esse é o único caso analisado aqui em que a aprendiz estuda português em uma faculdade a fim de se profissionalizar. Sua história de aprendizagem é muito interessante, apresentando diferentes tipos de contexto. Num primeiro momento, na Argentina, a aprendizagem foi considerada insuficiente pela aprendiz, devido ao tempo dedicado e à formação de seu professor. Já no Brasil, temos mais uma vez enfatizado o contato direto com a língua, que a aprendiz argentina considera como principal fator para o desenvolvimento de seu aprendizado, apesar de ter aulas particulares com uma professora nativa. Percebe-se, nessa narrativa, traços de autodirecionamento

${ }^{14}$ http://www.veramenezes.com/audiop24.htm. 
e de autonomia, à medida que a aprendiz, consciente da insuficiência de seu processo de aprendizagem, busca meios de complementá-lo, principalmente através do contato com nativos. A decisão de ingressar na Faculdade de Letras para aprofundar seu estudo de português também indica autodirecionamento e autonomia. Trata-se, porém, de mais um caso de semiautonomia (um estágio em que o aprendiz ainda não possui autonomia total sobre seu processo de aprendizagem, apenas sobre alguns aspectos), considerando-se a ligação da aprendiz com um contexto formal de aprendizagem. Pode-se dizer que a motivação nesse exemplo é extrínseca no início, já que a informante precisava aprender para vir morar no Brasil com o marido, e intrínseca num segundo momento, já que o gosto pessoal pela língua a levou a buscar um estudo mais aprofundado.

Um único caso de auto-instrução foi detectado:

\section{Narrativa 7:}

In fact I don't I need Portuguese for my work. I make a "pós-doutorado" here So my colleagues speak English very well. Our communication is in English, till now. And by the time I want to learn Portuguese, because I am [in country Brazil now...] everybody speak Portuguese, on the street, on the road, everywhere, so it is better to learn Portuguese if I found more time (...) I have just a book that you use in the course here in UFMG, Portuguese course for foreign language. And I try to follow the book, time to time, I want to finish every chapter. Sometimes people help me for learning all the sentences of the book. And I have dictionaries, English/ Portuguese, Portuguese/English, and also I have a book. (...) For my learn, just for day life practice, daily speech of sentences Portuguese/ Turkish, Turkish / Portuguese and pronunciation of Portuguese sentences in Turkish sounds. And there're some simple dictionaries, Turkish/ Portuguese, they help me, I hope so. And I use sometimes to define [the words] of Portuguese English, and friends support me, sometimes dictionaries, [...] And it is a good matter for me to live to live in a country people all speak Portuguese. (...) In fact I wanted to take a course but when I arrived here, the courses in UFMG it was because all had started before one month ago and I wasn't here. So it is not good to attend course after one month, for me. (...) I don't know their evaluation for determine language level [...] different classes I want to attend But the course is just two hours in the week and the course is just a bit expensive for two hours course. But it doesn't matter, it will not be problem, I can find a chance. I want to attend. ${ }^{15}$

\footnotetext{
${ }^{15}$ http://www.veramenezes.com/audiop34.htm.
} 
O pesquisador turco relata que não freqüenta um curso de português e que estuda o idioma sem o controle direto de um professor. É, portanto, um caso de auto-instrução. Mas concluir que tal aprendizagem exemplificaria o modelo máximo de autonomia definido por Dickinson (1987, p. 13) seria errôneo. Isso porque o aprendiz busca a ajuda de amigos nativos, inclusive para a escolha de material didático, que ele diz seguir passo a passo. Sua motivação não pode ser classificada como extrínseca, pois ele não precisa de português para cumprir suas tarefas no Brasil. Trata-se de um exemplo de motivação integrativa, já que o aprendiz estuda português porque é essa a língua falada pelas pessoas ao seu redor. O fato de ele não freqüentar um curso institucionalizado de português também não confere a esse caso um grau muito forte de autonomia, já que não é por opção do aprendiz, que admite até pretender fazê-lo. Um certo grau de autonomia e de autodirecionamento pode ser detectado em sua decisão de começar a estudar a língua mesmo fora de uma instituição, assim como na definição de tempo e conteúdo a ser estudado e na escolha de estratégias que lhe parecem mais eficazes. Considerando ainda as idéias de Littlewood (1996, p. 431), eu diria que esse aprendiz apresenta os três tipos de autonomia: como comunicador, visto que procura usar o português em situações do seu dia-dia no Brasil; como aprendiz, já que se dedica a um estudo usando estratégias próprias; e como pessoa, uma vez que cria contextos pessoais de aprendizagem.

$\mathrm{Na}$ análise das narrativas, também foram detectados exemplos que negam a idéia de que a autonomia seja uma noção praticamente ocidental, pouco desenvolvida por aprendizes orientais (HO; CROOKALLT, 1995). Foram entrevistados quatro aprendizes japoneses, um chinês e um malaio (citado na narrativa 5), dos quais nenhum apresentou objeção ao uso de estratégias tipicamente autônomas, como buscar meios diferentes e usar a língua fora da sala de aula. Os trechos a seguir são parte das narrativas de uma aprendiz japonesa e de um aprendiz chinês, respectivamente.

\section{Narrativa 8:}

(...) eu preciso fazer muitos exercícios, né? Porque para escrever, para mim [é] muito difícil. So... meu problema é não falar bem porque eu não escrevo bem. So, para mim, eu preciso escrever muitos textos de como fala, isso. Agora eu queria escrever mais, ou de [...] também. Mas isto é structure, né? Structure, I understand. I am becoming understood. But I didn't, I didn't know anything about. I... so, difícil, né? I speak... English but it is completely different, né? Adjectives, vowels and any more matter, né? I still manage it, I guess, and I need someone to talk everytime, né? But sometimes I put 
away to they correct me I feel not to talk anymore, you see? But if they don't correct me, I don't improve, né? So I try to read a book, as much as I can, and I... have to... I have to write well, I mean... how to... So pronunciation in Portuguese is not difficult, you pronounce as you write. So, I want to try my best. ${ }^{16}$

\section{Narrativa 9:}

Eu estudo português na UFMG, intermediário 1 e intermediário 2, os cursos, e já fiz o curso básico. E eu tenho amigos brasileiros; eles sempre falam português comigo. E também eu leio livros em português, eu vejo novela, eu vejo filme, eu vejo televisão. Eu também leio jornais. Só isso. ${ }^{17}$

Na primeira narrativa, percebe-se claramente uma consciência das próprias necessidades de melhora, busca de meios para satisfazê-las e esforço para manter contato com nativos. Na segunda, o aprendiz busca o contato direto com a língua, conversando com nativos e usando materiais autênticos. Isso me leva a considerar que ambos os aprendizes apresentam características de semi-autonomia. O que não posso afirmar com certeza quanto aos aprendizes orientais é se o fato de estarem vivendo num país onde sua língua alvo é falada pode alterar ou amenizar a preferência por abordagens mais institucionalizadas, característica inerente aos povos orientais. Na verdade, as informações disponibilizadas pelos meus informantes não são suficientes para uma análise mais profunda dessa questão.

\section{Conclusão}

A análise das narrativas de estrangeiros estudando português no Brasil com base na literatura sobre autonomia possibilitou a seguinte formulação: o contato direto com a língua estrangeira, ou seja, a inserção do aprendiz no contexto em que ela é usada por seus falantes nativos, oferece um ambiente mais propenso à autonomia. Isso se comprova pela observação nas narrativas da ocorrência de diversos traços característicos de autonomia, diretamente relacionados ao contexto analisado. A saber, esses traços são:

1) consciência das próprias necessidades no processo de aprendizagem do português;

\footnotetext{
${ }^{16} \mathrm{http}: / /$ www.veramenezes.com/audiop35.htm.

${ }^{17}$ http://www.veramenezes.com/audiop14.htm.
} 
2) tomada de decisão sobre metas, contextos de aprendizagem, programa de estudos (determinação de conteúdo e de tempo) e estratégias;

3) uso do português em situações de própria escolha fora da sala de aula;

4) busca de meios e materiais diferentes daqueles disponibilizados pela instituição de ensino formal e escolha desses meios e materiais de acordo com os próprios interesses e necessidades;

5) motivação, na maioria dos casos intrínseca e/ou integrativa;

6) exercício de autonomia como comunicador (criatividade e uso de estratégias para comunicar significados em situações específicas), como aprendiz (uso de estratégias de aprendizagem independentemente do contexto formal) e como pessoa (criação de contextos pessoais de aprendizagem e expressão de sua individualidade), beneficiado pela situação de aprendizagem de português durante estadia no Brasil.

Percebi que a maioria dos aprendizes entrevistados demonstrava ter consciência das próprias necessidades e tomava decisões sobre a aprendizagem de acordo com elas. Essas decisões vão do simples fato de escolher o nível de curso em que se matricular - básico, intermediário I, intermediário II, ou avançado, no caso do Curso de Português para Estrangeiros do CENEX/ FALE - até o uso de estratégias específicas e focalização num determinado tipo de atividade ao estudar fora da sala de aula. Dentro dessas estratégias, está a busca de meios materiais diferentes daqueles usados em aula. Nas narrativas analisadas, essa busca pode se estender do uso materiais didáticos diferentes - outros livros, gramáticas, dicionários especializados, CD-ROM, etc. - até uma exposição maior à língua e a materiais autênticos - revistas, literatura, filmes, rádio, televisão, Internet, conversa com falantes nativos. Ao escolher o meio ou material, o aprendiz leva em conta, além de suas necessidades, seus gostos e sua experiência enquanto aprendiz.

Quanto à motivação, considero que o fato de esta se apresentar como intrínseca e/ou integrativa na maioria dos casos analisados tem a ver com o contexto de aprendizagem. Primeiro, porque o fato de estar aprendendo português no Brasil por si só já representa uma busca por integração com os falantes nativos, seja por necessidade ou por interesse pessoal nesse contato. Segundo, porque a decisão de vir estudar português no Brasil, a busca de opções de estratégias em meio a uma extensa série de possibilidades e o uso intenso dessas estratégias estão mais relacionados à motivação intrínseca. 
Em termos das gradações de autonomia propostas por Dickinson (1994, p. 11), os dados incluem apenas um aprendiz identificado como caso de auto-instrução. No entanto, foi percebido um certo grau de autodirecionamento em todas as narrativas analisadas, assim como um certo grau de autonomia, o que me leva a classificar os informantes como semiautônomos. Nenhum caso foi identificado como instrução individualizada ou como autonomia total. Embora o caso do aprendiz turco, ilustrado na narrativa 7, se aproxime do ideal de autonomia nas definições de Dickinson, concluí aqui que o fato de esse se tratar de um caso de auto-instrução não é suficiente para permitir tal classificação. Esse aprendiz só estuda sozinho porque não conseguiu se matricular em um curso tradicional e confia no material didático escolhido por esse curso, tanto que o adota, demonstrando, com isso e com o fato de ser auxiliado diretamente por falantes nativos, dependência de um direcionamento externo.

Concluí, ainda, que identificar traços de autonomia nas narrativas de estrangeiros que estudam português no Brasil possibilita não apenas analisar estratégias de aprendizagem mas também perceber atitudes (como o esforço para se inserir culturalmente na comunidade) num meio em que a interação com falantes nativos e o contato direto com a língua estudada são intensos. Mais uma vez, aponto aqui a validade das considerações de Paiva (2004, p. 8), para quem autonomia é um sistema sócio-cognitivo complexo, manifestado pelo indivíduo tanto como aprendiz de língua quanto como comunicador dentro ou fora da sala de aula.

Esta pesquisa, no entanto, foi apenas uma tentativa de identificar os principais pontos característicos de uma aprendizagem autônoma, visto que esse conceito é na verdade muito mais complexo, abrangendo diversas áreas do conhecimento e da vida social.

Acredito ter contribuído para uma idéia de como a autonomia pode ser identificada entre aprendizes expostos mais diretamente a uma língua estrangeira, apontando os principais pressupostos encontrados na literatura que se aplicam a esse contexto de aprendizagem, e contribuindo para a formação de um corpus para pesquisas futuras. Reconheço, porém, a necessidade de se tratar mais profundamente do assunto, em pesquisas para as quais o presente trabalho procurou apontar caminhos. Questões como a influência da cultura do aprendiz estrangeiro - principalmente em se tratando de aprendizes orientais - na aprendizagem de português no Brasil, e a influência desse contexto para o grau de autonomia alcançado pelo aprendiz precisam ainda ser mais detalhadamente analisadas. 


\section{Referências Bibliográficas}

BENSON, P. The philosophy and politics of learner autonomy. In: BENSON, P.; VOLLER, P. (Org.). Autonomy \& independence in language learning. New York: Addison Wesley Longman, 1997. p. 18-34.

BENSON, P.; VOLLER, P. Introduction: autonomy and independence in language learning. In: BENSON, P.; VOLLER, P. (Org.). Autonomy $\varepsilon$ independence in language learning. New York: Addison Wesley Longman, 1997. p. 01-17.

CHAIX, P.; O'NEIL, C. A critical analysis of forms of autonomous learning (Autodidaxy and Semi-autonomy) in the field of Foreign Language Learning. Final report. UNESCO Doc. Ed 78/w5/58, 1978.

CROOKES, G.; SCHMIDT, R. W. Motivation: reopening the research agenda. Language Learning, v. 41, n.8, p. 469-512, December 1991.

DECI, E. L.; RYAN, R. M. Intrinsic Motivation and Self Determination in Human Behavior. New York: Plenum Press, 1985.

DICKINSON, Leslie. Self-instruction in language learning. Cambridge: Cambridge University Press, 1987. 200 p.

DICKINSON, Leslie. Autonomy and Motivation: A Literature Review. System, v. 23 , n. 2, p. 165-174, 1995.

HOLEC, Henri. Autonomy and foreign language learning. Strasbourg: Council of Europe Education and Culture, 1980.

HO, Judy; CROOKALLT, David. Breaking with Chinese cultural traditions: learner autonomy in English language teaching. System, v. 23, n. 2, p. 235-243, 1995.

LITTLE, David. Learner autonomy and second/foreign language learning. Disponível em: <http://www.lang.ltsn.ac.uk/resources/goodpractice.aspx? resourceid=1409>. Acesso em: 22 Jul. 2003.

LITTLEWOOD, William. "Autonomy": An Anatomy and a Framework. System, v. 24, n. 4, p. 427-435, 1996.

PAIVA, Vera L. M. O. Autonomia e Complexidade: uma análise de narrativas de aprendizagem. Linguagem e Ensino, v. 9, n. 1, p. 77-127, 2006. 